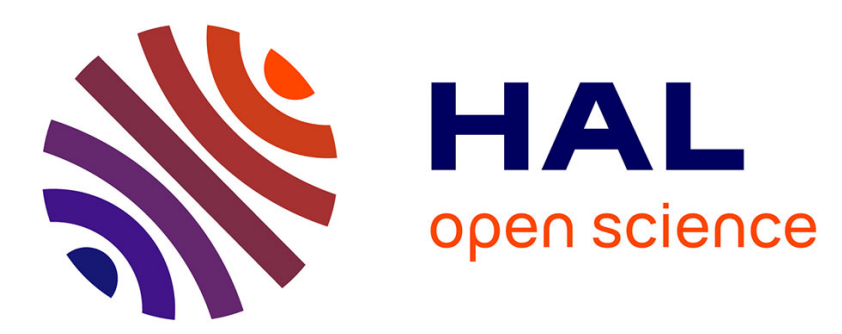

\title{
A bioenergetics model of the entire life cycle of the three-spined stickleback, gasterosteus aculeatus
}

Charlène Leloutre, Alexandre R.R. Pery, Jean-Marc Porcher, Rémy Beaudouin

\section{To cite this version:}

Charlène Leloutre, Alexandre R.R. Pery, Jean-Marc Porcher, Rémy Beaudouin. A bioenergetics model of the entire life cycle of the three-spined stickleback, gasterosteus aculeatus. Ecology of Freshwater Fish, 2018, 27 (1), pp.116-127. 10.1111/eff.12329 . hal-01673454

\section{HAL Id: hal-01673454 https://hal.science/hal-01673454}

Submitted on 27 Feb 2020

HAL is a multi-disciplinary open access archive for the deposit and dissemination of scientific research documents, whether they are published or not. The documents may come from teaching and research institutions in France or abroad, or from public or private research centers.
L'archive ouverte pluridisciplinaire HAL, est destinée au dépôt et à la diffusion de documents scientifiques de niveau recherche, publiés ou non, émanant des établissements d'enseignement et de recherche français ou étrangers, des laboratoires publics ou privés. 


\section{A BIOENERGETICS MODEL OF THE ENTIRE LIFE-CYCLE OF THE}

2 THREE-SPINED STICKLEBACK, GASTEROSTEUS ACULEATUS

C. Leloutre*, A.R.R. Péry†ं, J.M. Porchert, and R. Beaudouin*

4 * Unit of Models for Ecotoxicology and Toxicology (METO), INERIS, 60550 Verneuil en 5 Halatte, France. Tel: +33344618238; e-mail: remy.beaudouin@ineris.fr

6 Unit of Ecotoxicological Risks Assessment (ECOT), INERIS, 60550 Verneuil en 7 Halatte, France.

$8 †$ UMR ECOSYS, INRA, AgroParisTech, Université Paris-Saclay, 78026, Versailles, 9 France

11 A whole life-cycle bioenergetic model based on the Dynamic Energy Budget (DEB) theory 12 was proposed for the three-spined stickleback (Gasterosteus aculeatus). To develop this 13 model, experiments on growth and reproduction were performed: adult and juvenile growth, 14 size at first reproduction, and amount of eggs spawned by females were monitored under 15 different feeding levels and temperatures. The DEB parameters were estimated, using 16 Bayesian statistics, based on the data produced during these experiments and on other data

17 found in the literature. The model fitted accurately the different data used for the calibration 18 process and, in addition, predicted accurately the datasets used to assess its predictability. Our 19 bioenergetic model of the whole life cycle of the three-spined stickleback accounting for

20 environmental variations could contribute in many ways to improved ecological assessment:

21 supporting change of scale from individual to populations; developing new biomarkers of 22 exposure and effect; analysing ecotoxicity tests with biology-based models.

24 Key-words: Dynamic energy budget, Bayesian statistics, growth, reproduction, environmental 25 variations 


\section{INTRODUCTION}

27 The three-spined stickleback Gasterosteus aculeatus is a small-bodied teleost fish which

28 constitutes a major component of shallow water food webs in the Northern hemisphere.

29 Actually, stickleback can play an important role in ecology by dominating fish communities

30 or affecting ecosystem functioning (Harmon et al. 2009). For example, it can compete with

31 economically valuable species, such as salmonids or cottids, in resource-limited environments

32 (Hovel et al. 2015). The three-spined stickleback is a model species for experimental studies

33 in aquatic evolutionary biology, ecology, and behaviour. For instance, numerous field and

34 laboratory studies on the reproductive behaviour of G. aculeatus and on the consequences of

35 global warming for aquatic species were carried out on this species (Wootton 1984). G.

36 aculeatus is also considered as a good sentinel fish species in aquatic ecotoxicology

37 (Pottinger et al. 2002). Experiments have been carried out in field or semi-field conditions to

38 assess the impacts of pollutants at the population level (Maunder et al. 2007; Roussel et al.

39 2007a; De Kermoysan et al. 2013).

40 Mathematical models are increasingly used in ecological risk assessment, due to the rise in

41 demand for ecological realism in regulatory risk assessment (Forbes et al. 2011). Models are

42 conveniently used to upscale from individual level to population level (Beaudouin et al. 2012;

43 Goussen et al. 2013; Martin et al. 2013; Beaudouin et al. 2015). However, their development

44 requires a large amount of data on the life cycle of the organisms (Péry et al. 2003; Goussen

45 et al. 2013; Beaudouin et al. 2015). Mechanistic models of the bioenergetics of organisms,

46 accounting for environmental variations (for example energy resources, temperature), offer a

47 realistic description of the life cycle of individuals (growth, reproduction, survival...). They

48 can also contribute to reduce the data necessary to develop a model of population dynamics

49 when they explicitly link feeding, growth, and reproduction (Beaudouin et al. 2012). 
50 Accounting for energy in population models also allows to assess how energy is shared

51 between different species competing for the same resource, for instance stickleback and

52 economically valuable species (Hovel et al. 2015). Finally, bioenergetics models have already

53 proved to be useful to assess the effects of toxic compounds (Kooijman \& Bedaux 1996; Péry

54 et al. 2003; Jager et al. 2004; Billoir et al. 2008; Goussen et al. 2013; Goussen et al. 2015).

55 Bioenergetics models were already developed for G. aculeatus adults and were used to

56 compare the bioenergetics pathways for a variety of populations in relation to both individual

57 variations and environmental conditions (Wootton and Evans 1976; Wootton et al. 1978;

58 Wootton et al. 1980; Wootton 1994). However, these models did not integrate the effect of

59 temperature on the physiological parameters (Wootton 1994). Recently, a bioenergetics model

60 has been developed for the three-spined stickleback to determine mass- and temperature-

61 dependent functions for maximum consumption and routine respirations costs (Hovel et al.

62 2015). However, an integrated model describing the dynamics of energy from larvae to adults,

63 linking feeding, growth and reproduction has still not been developed.

64 The bioenergetics models commonly found in the literature are based on strong empirical 65 foundations and are very helpful to synthesize data. Theory-driven models such as those 66 based on the Dynamic Energy Budget (DEB) theory (Kooijman 2000), go a step further, by 67 providing a description of the whole life cycle, with parameters able to account for intra68 species and inter-species variations as explained by Nisbet et al. (2012). As shown by these 69 authors, the traditional bioenergetics models are in fact special cases of a DEB model. When 70 the focus is on the entire life-cycle, and provided the assumptions of standard DEB theory 71 apply, a DEB model would have fewer parameters than common bioenergetics models. DEB 72 theory has been used to answer different questions in ecology of fishes: management in 73 fisheries (Jusup et al. 2011), prediction of the growth and reproduction during spawning 
74 migration (Pecquerie et al. 2009; Einarsson et al., 2011) or under different environmental

75 conditions (Rinaldi et al. 2014), and comparison of life strategies between species (van der

76 Veer et al. 2001; Freitas et al. 2010; Pecquerie et al. 2011). Moreover, nesting a DEB model

77 within a population dynamics model provides realistic descriptions and predictions of

78 population dynamics, especially when populations are facing food limitations (Beaudouin et 79 al. 2015).

80 The aim of this study was to develop an entire life-cycle model, based on the DEB theory,

81 for G. aculeatus to predict the main physiological processes (growth, reproduction, puberty)

82 in different environmental conditions, i.e., temperature, feeding. To achieve this aim, we

83 produced and collected data on growth, on larvae development, maturity, and reproduction.

84 The model was calibrated on these data using Bayesian statistics. Before the calibration, a 85 sensitivity analysis of the DEB model was carried out. Finally, the predictive capacity of the 86 model was evaluated.

\section{MATERIALS AND METHODS}

G. aculeatus used in laboratory experiments came from field population located in the

90 vicinity on the experimental facilities and were reared in laboratory condition during six

91 months before the experiments (INERIS, Verneuil-en-Halatte, France). The ethics committee

92 of the National Institute of Industrial Environment and Risks (INERIS) approved all the

93 experiments performed and described in this manuscript.

94 In order to develop the DEB model, experiments were performed outdoor in semi95 controlled conditions and indoor in controlled conditions. The outdoor experiments were 96 conducted in experimental rivers under natural scenario of temperature (fluctuating) and 97 under natural photoperiod. These experiments aimed to focus on the response of the growth of 
98 juveniles and the fecundity of females to different scenarios of temperature and feeding level.

99 Our experimental rivers are described in detail in de Kermoysan et al. (2013). The indoor 100 experiment under controlled conditions (i.e. with a constant fixed temperature and

101 photoperiod) aimed to measure the growth of G. aculeatus (juveniles and adults) as a function 102 of temperature and feeding level. Fish were placed under a constant photoperiod of 14:10-h 103 light:dark.

\section{Water quality}

105 For all experiments, water temperature was recorded every ten minutes with a water 106 temperature sensor (HOBO0257, Prosensor, Amanvillers, France). Water parameters (pH, 107 conductivity and dissolved oxygen) in the outdoor experiments were monitored and kept 108 suitable for the development of G. aculeatus. In the indoor experiments, the tank was filled 109 with denitrified and dechlorinated tap water continuously renewed $\left(1 \mathrm{~L} \mathrm{~h}^{-1}\right)$.

\section{Length measurement of fish}

111 The standard length was measured (from mouth to the base of the caudal fin) by 112 photography. Individuals were placed on a graph paper in a crystallizer containing a few

113 millimetre of water. Then the individuals were measured using the ImageJ software (Rasband 114 1997).

$115 \quad$ Feeding

116 In the experiments, feeding level was adjusted (i.e., mass a food provided) at the time of 117 measurement to be maintained as a constant ratio of the fish mass. The fish weight was 118 deduced from the measured standard length using allometric relationship calibrated on data 119 obtained during previous experiments (Fig 1A and 2A, Supporting Information). Adult food 
120 was composed of frozen chironomid larvae and juveniles were fed with Artemia newly 121 hatched.

122 Experiment 1: Egg development and dynamic of yolk sac absorption

123 To determine the duration of the embryonic development from fertilization to hatching, a 124 pool of 250 unfertilized eggs obtained from 10 females were in vitro fertilized and incubated 125 at constant temperature (methods presented in Santos, 2013a). The actual temperature was 126 monitored every in continue. The number of hatched eggs was counted four times a day since 127 the first hatching was observed. Hatching was considered achieved when at least $50 \%$ of the 128 eggs are hatched.

129 As above, to determine the dynamic of yolk absorption, a pool of fertilized eggs obtained 130 from 10 females was used to randomly select four groups of 20 individuals which were 131 monitored from hatching to full yolk absorption. The evolution of the size of the yolk sac was 132 monitored three times per day for eight days. To this purpose, the juveniles were observed 133 under a binocular microscope and scored on five ( 5 for a full yolk sac and 0 for the absorption 134 of the yolk sac). Yolk absorption was considered achieved when at least $50 \%$ of individuals 135 scored 0.

136 The eggs and juveniles were introduced into beakers (diameter: $11.5 \mathrm{~cm}$, height: $4 \mathrm{~cm}, 400$ $137 \mathrm{~mL}$ of water) placed in a water bath having a nominal temperature of $14.5{ }^{\circ} \mathrm{C}$. Two thirds of 138 the water was renewed every day.

139 Experiment 2: growth of juveniles under controlled conditions/under natural conditions

140 The aim of these experiments was to monitor the growth of juveniles under different 141 temperature and feeding scenarios. Each group was composed of 20 juveniles and 142 experiments were initiated with newly hatched juveniles with completely absorbed yolk. A 143 pool of fertilized eggs obtained from 10 females was used to randomly select the individuals 
144 of the groups. The daily rations were provided in two feeding events per day. The number of

145 dead fishes was monitored twice a day at the feeding (Table 1A; Supporting Information).

146 The actual food rations ( $\mathrm{mg}$ of food per individual per day) were computed for each group at

147 the end of experiment. The lengths were measured on photographs taken at the initial time

148 and at the end of the experiment.

149 We placed 43 groups, each in a $15 \mathrm{~L}$ aquarium, under controlled conditions. The nominal 150 exposure temperatures were $5,10,15,20$, and $22^{\circ} \mathrm{C}$ and were maintained constant in time.

151 This range of temperature was chosen according to the study by Lefébure et al. (2011). The

152 feeding level varied from 5 to $80 \%(5,10,20,40,60$, and $80 \%)$ of the fish mass. For a given 153 temperature, at least five different feeding levels were tested. Measured average temperatures 154 and feeding level are summarized in Supporting Information A.2. These experiments lasted 155 four days.

156 We placed 9 groups under outdoor conditions in enclosures $(20 \mathrm{~cm} \times 20 \mathrm{~cm} \times 15 \mathrm{~cm})$ in 157 experimental rivers. Fish were fed from 10 to $60 \%$ of their mass, for six days and the 158 temperature varied from $15.9{ }^{\circ} \mathrm{C}$ to $20.4^{\circ} \mathrm{C}$. These experiments were performed at different 159 times from May to August.

160 Experiment 3: growth of adults

161 To minimize the food competition and facilitate feeding, three mixed-sex fish groups of 162 similar length were defined at the beginning of the experiment: small (length approximately $16330 \mathrm{~mm}$; 30 unsexed fish), medium (length approximately $40 \mathrm{~mm}$; seventeen females and 164 fourteen males) and large (approximately $60 \mathrm{~mm}$ long; nineteen females and eleven males) 165 fish groups. The small and medium groups were placed in tanks of 300 litres. The large group 166 was sub-divided into two groups and placed in 300 litres tanks to lower the density in each 167 tank. The length was monitored in males and females during 55 days and each fish was 
168 measured every ten days. Fish were individually marked with alphanumeric tags (method

169 detailed in de Kermoysan et al. (2013)) and the sex of the fish was identified at the end of the

170 experiment by examining the gonads under binocular microscope. For this experiment, the

171 tanks were placed indoor with natural light and non-controlled temperature. Dechlorinated

172 and denitrified tap water continuously renewed $\left(1 \mathrm{~L} \mathrm{~h}^{-1}\right)$ was used to fill the tank (very small

173 daily variation) and they were exposed to natural photoperiod (from April to June). The

174 temperature was monitored continuously (daily mean temperature was from $13.9 \pm 0.3$ to 18.8

$175 \pm 0.5^{\circ} \mathrm{C}$; mean \pm S.D.). Adults were fed ad-libitum.

176 Experiment 4: fecundity of females

177 The aim of this experiment was to determine the number of eggs by clutch. This 178 experiment was performed under outdoor conditions: fluctuant temperature (from 11.0 to $17919.3^{\circ} \mathrm{C}$ ) and natural photoperiod (May to August). Three pool of females (15 individuals) kept 180 in tanks of 300 litres and fed ad-libitum, were observed daily. Among these females, when 181 one female was ready to spawn, it was selected, anesthetized (MS-222), measured and then 182 stripped, i.e. mature eggs were retrieved by gently pressing the abdomen of the female 183 pectoral fin to the tail (the method is detailed in Santos et al. (2013b)).

184 During the entire experiment, 34 clutch sizes were collected from 34 females ready to 185 spawn, and were stripped. The females were not marked and we do not know the number of 186 clutches produced by each female. According to our experiments, a margin of error of about $1875 \%$ was observed in the egg recovery (dissection of some females after euthanasia to check 188 the method). After a recovery period, the fish was released in its tank and the eggs released 189 were counted.

190 Experiment 5: length at maturity of males 
191 The maturity states of 115 males measuring from 23 to $47 \mathrm{~mm}$ were determined. Males were

192 caught in the field population (natural temperature and photoperiod) and growth under natural

193 temperature and photoperiod. To this purpose, the fish were killed using a high dose of MS-

194 222. Thereafter, fish standard length was measured, and sex was determined by visual

195 observation of the gonads. Maturity states of the males were determined by observation under

196 a stereo microscope and two groups were distinguished: immature and mature (Craig-Bennett

197 1931; Sokolowska and Kulczykowska 2006). A log-normal distribution was adjusted on the

198 frequency by length classes of male with mature gonads to determine the median length at

199 maturity (Supporting Information A.4).

200 MODEL STRUCTURE

201 In this study, we used a DEB model. The model of the DEB theory describes the rate at

202 which the organism assimilates and uses energy for maintenance, growth, and reproduction as

203 a function of its state (energy density and size) and its environment (i.e. food density and

204 temperature; Fig .1). Allocation to growth and somatic maintenance occurs in parallel to 205 allocation to maturation and reproduction (Fig. 1). A description of the DEB model in fish is 206 well detailed in Augustine et al. (2011) and Pecquerie et al. (2009). All the equations of the

207 DEB model are presented in Supporting Information B. Parameters are listed in Table 1 using 208 standard DEB notation.

209 The growth simulation in the DEB model of $G$. aculeatus starts in a primordial cell $\left(L_{0}\right.$, in $210 \mathrm{~mm}$ ). Just after hatching, larvae have a yolk sac (energy storage necessary for growth until 211 juvenile stage). Once the yolk sac is absorbed, juveniles start feeding. There is no assimilation 212 during the embryonic period. The metamorphosis between the larvae and the juvenile stage 213 and between the juvenile and the adult stages occurs when energy invested in maturity 214 reaches specific thresholds. 
Male G. aculeatus have a smaller maximal size than females (Wootton 1984) and a smaller

216 growth rate after puberty, as observed in our experiments. To model this difference, we

217 assumed a type R metabolic acceleration (Kooijman, 2014). Contrary to females for which the

218 parameter $\kappa$ (the fraction of energy allocated to growth and somatic maintenance) is invariant

219 in time, the value of $K$ in males decreases when the individuals reach their maturity $\left(E_{H}=E_{H}^{p}\right)$,

220 which gives: $\kappa_{\text {males }}=\kappa-\alpha$, with alpha the fraction subtracted for $\kappa$ in males G. aculeatus.

221 Parameter $f$, the feeding ratio, was computed from the following equations:

$$
\text { If } W_{F}<W_{F, \text { ad-lib }} \text { then } f=\frac{W_{F}}{W_{F, a d-l i b}}=\frac{W_{F}}{\varphi \cdot L^{2}}
$$

$$
\text { If } W_{F}>=W_{F, \text { ad-lib }} \text { then } f=1
$$

224 where $W_{F}$ is the energy available for a fish per day (in $\mathrm{J}$ ). $W_{F}$ is computed from the actual 225 daily mass of food (mg) per fish and the energy density for the different preys, 2326, 3730 and $3427 \mathrm{~J} / \mathrm{g}$ wet weight for the nauplii of Artemia sp, the larvae of Chironomus sp and the

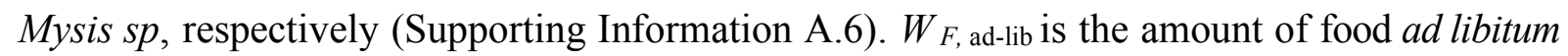

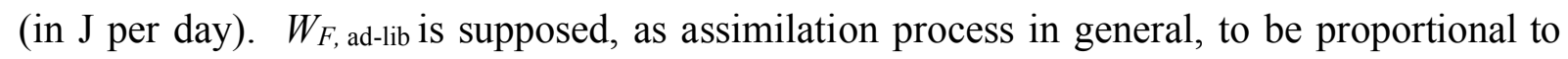

229 the squared length. $\varphi$ is a proportionality factor.

230 Nauplii of artemia was provided as a volume of solution, and converted in mass using the 231 volume-weight relationships provide in Supporting information A.5. To take into account the 232 uncertainty of this relationship and on the energy density of the nauplii, an uncertainty factor 233 (noted Fc), a priori equals to one, was used to modulate the value of $W_{F}$ (Eq. 3) when fish 234 were fed with brine shrimp nauplii.

235 In ectotherms, physiological processes depend on the environmental temperature. The 236 primary parameters used in the DEB model were corrected depending on the temperature 237 using a temperature correction function approximated with the Arrhenius temperature 
238 (Kooijman 2000). As shown by Lefébure et al. (2011) and Hovel et al. (2015), the Arrhenius 239 relationship can be assumed for the G. aculeatus only within a particular temperature range

240 from the minimal temperature $\left(3-5^{\circ} \mathrm{C}\right)$ to the optimal temperature for growth $\left(21-23^{\circ} \mathrm{C}\right)$

241 (Supporting Information B.3). Consequently, in our DEB stickleback model, we proposed to 242 use a temperature correction function defined for warmwater fishes (Kitchell et al. 1977) and 243 adjusted for the stickleback by Hovel et al. (2015). This function, named $T_{\text {effect }}$, provided 244 results similar to the function proposed by Lefébure et al. (2011) (Supporting Information 245 B.3):

$$
\begin{aligned}
& T_{\text {effect }}=\left(\frac{T_{\text {max }}-T_{\text {exp }}}{T_{\text {max }}-T_{\text {opt }}}\right)^{X} \cdot e^{X-X \cdot\left(\frac{T_{\text {max }}-T_{\text {exp }}}{T_{\text {max }}-T_{\text {opt }}}\right)} \\
& X=\frac{Z^{2} \times\left(1+\sqrt{1+\frac{40}{Y}}\right)^{2}}{400} \\
& Z=\log (C q) \times\left(T_{\text {max }}-T_{o p t}\right) \\
& Y=\log (C q) \times\left(T_{\text {max }}-T_{o p t}+2\right)
\end{aligned}
$$

250 where, $T_{\max }$, is the water temperature above which consumption ceases, $T_{\text {opt }}$ is laboratoryderived temperature preferendum, $C q$ approximates the rate at which the function increases

252 over low temperatures and Texp is the experiment temperature. Parameters $\dot{v}$, the energy 253 conductance $\left(\mathrm{mm} \mathrm{d}^{-1}\right),\left\{\dot{p}_{A m}\right\}$, the maximum surface area specific assimilation rate $\left(\mathrm{J} \mathrm{mm}^{-2} \mathrm{~d}^{-}\right.$ $\left.254{ }^{1}\right),\left[\dot{p}_{M}\right]$, the volume specific somatic maintenance costs $\left(\mathrm{J} \mathrm{mm}^{-3} \mathrm{~d}^{-1}\right)$, $255 \dot{k}_{J}$, maturity maintenance rate $\left(\mathrm{d}^{-1}\right)$ and $\varphi$ were corrected with this equation. This last 256 parameter is corrected to take into account the acceleration or deceleration of assimilation 257 impacting on the amount of food available.

\section{Statistical analysis of data}


First, the effect of the temperature and/or the feeding level on the daily growth in juveniles

261 (experience $2 ; n=53$ ) was analyzed using a linear model. Secondly, the effect of the sex

262 (male or female) on the standard size of adults (experience 2, three mixed groups, $\mathrm{n}=75$ ) was

263 analyzed using an ANCOVA. The time was used as covariate and the sex as factor. Finally,

264 for the experience 4 , we tested whether the clutch size $(n=34)$ depends of the female

265 standard lengths and the water temperature by using an ANCOVA. The standard length of 266 female was incorporate as covariate and the temperature as factor.

\section{Sub-models for non-measured data}

268 As successive spawns by the same female were difficult to observe, we had to estimate the 269 inter-spawning interval (i.e., the time between two spawns) and the standard length of the 270 female at the beginning of the inter-spawning interval for each spawn observed in our 271 experiments. To this purpose, an equation which predicted the inter-spawning interval (ISI) 272 according to the water temperature (equation 7) was fitted to the data published by (Wootton 273 et al. 1980; Bolduc \& FitzGerald 1989; Boulé \& Fitzgerald 1989).

$$
I S I=0.748 \times \bar{T}+26.416
$$

275 where $\bar{T}$ is the daily mean temperature (in ${ }^{\circ} \mathrm{C}$ ). This equation gives the number of days 276 between two consecutive spawns. Based on the interval estimated for each female, the length 277 at the beginning of the ISI was estimated assuming growth occurring in optimal conditions.

278 We checked, a posteriori that this choice did not affect the calculation of the length by more 279 than 1\% compared to the calibrated model (Table 4C and Fig 6C, Supporting information).

280 Sensitivity analysis

281 We performed sensitivity analysis of the DEB model to identify the main contributing 282 parameters to changes in model outputs. This was performed using the Sobol' method 
283 (Saltelli 2002). This analysis is based on a functional decomposition of the variance, and is 284 recommended in the case where the model is non-linear and non-monotonic. In order to 285 estimate Sobol' indices, a Monte Carlo approach was used. Two input sample matrices $(n \times$ $286 p)$ where $n$ is the sample size $(n=10,000)$ and $p$ the number of parameters $(p=16$ for the SA 287 of females and $p=17$ for males) were used. Parameter distributions were uniform and the 288 lower and upper limits were defined $\pm 10 \%$ around a priori values. Then, we calculated the

289 first order (FOI; variance contribution on one parameter) and the total order (TI; main effect 290 of one parameter and all its interactions with the other parameters) Sobol' index. To assess 291 confidence intervals on the estimation of Sobol's indices, bootstrapping was used $(1,000$ 292 times sampled with replacement). The sensitivity analysis was carried out with sensitivity R293 package using the function soboljansen (Pujol et al. 2012) with the statistical computing 294 software R (R Core Team, 2014). Sobol' sensitivity indices were estimated for the growth at 29520,100 and 650 days post fecundation (dpf), for the energy invested in maturity at 20, 50 and $296150 \mathrm{dpf}$, and for the energy invested in reproduction at 150, 400 and $650 \mathrm{dpf}$.

297 Model calibration

298 The calibration of G. aculeatus DEB model was performed using the software R with the 299 coda package (Plummer et al. 2015) and MCSim, which is designed for Bayesian inference 300 through Markov Chain Monte-Carlo (MCMC) (Bois 2009). We performed three independent 301 MCMC and the quality of convergence was checked by calculating the Gelman-Rubin index 302 (Gelman et al. 1996).

303 The likelihood functions were defined assuming that the observations: length, number of 304 eggs per clutch, size at sexual maturity, and length and age at larvae-juvenile metamorphosis 305 (absorption of the yolk sac, first external feeding), were associated with normally distributed 306 residual errors. The standard deviation of the residual errors of the growth and reproduction 
was adjusted with a half normal distribution, and fixed at the estimated values on the data for

308 the two other endpoints (Table 2B in Supporting Information B).

309 The a priori distribution of the parameters were defined based our experimental data or 310 using the addmypet database (www.bio.vu.nl/thb/deb/deblab/add_my_pet). When enough

311 data were available for a given parameter, a priori distributions of the parameters values were 312 defined by a normal distribution, and otherwise, we used a uniform distribution (Table 1).

\section{EXPERIMENTS USED TO EVALUATE PREDICTIVE CAPACITY}

314 Data were produced to assess the predictability of our DEB model. To evaluate the growth

315 predictions, two different experiments were performed. Each experiment lasted three weeks in 316 semi-controlled conditions (natural scenario of temperature and under natural photoperiod).

317 For each experiment, three groups were introduced in enclosure $(25 \times 25 \times 30 \mathrm{~cm}$ with mesh 318 to 500 microns) in experimental river. Experiments were performed at two different periods 319 of the same year (May and July). Juveniles of the first experiment (May, 30 fishes per group) 320 were fed with similar level of food (percentage of the fish mass) for the first and third weeks, 321 and with a smaller during the second week (Table 2A in Supporting Information A). The 322 juveniles of the second experiment (July, 40 fishes per group) were fed to a higher constant 323 level of food (percentage of the fish mass), readjusted at each length measurement (Table 2A 324 in Supporting Information A).

325 For the reproduction part, the calibration dataset (training set) was constituted using a 326 dataset where eleven out of the 34 clutch sizes were randomly removed ( $1 / 3$ female) from the 327 data produced in Experiment 4. The eleven clutch sizes randomly removed were used to 328 evaluate the predictive capacity of the model, and then constituted the test set. Finally, once 329 the predictive capacity had been checked, a global calibration was performed with the whole 330 dataset. 


\section{EXPERIMENTAL DATA}

333 The embryonic development from fecundation to hatching of 50\% of the viable eggs (229 334 eggs) lasted 12.9 days at $13.1 \pm 0.8^{\circ} \mathrm{C}$ (mean \pm S.D.). The yolk sac absorption in larvae in 335 experiment 1 lasted 48 hours for four groups at $15.7 \pm 0.02{ }^{\circ} \mathrm{C}$ (mean \pm S.D.).

336 In the experiment 2, the growth of juveniles was significantly altered by the feeding ratio 337 (linear model, $\mathrm{t}=5.81, \mathrm{df}=2, \mathrm{P}<0.001, \mathrm{R}^{2}=0.77$ ) and the temperature (linear model, $\mathrm{t}=$ $\left.11.57, \mathrm{df}=2, \mathrm{P}<0.001, \mathrm{R}^{2}=0.77\right)$. There is no interaction between the feeding ration and the temperature (linear model, $\mathrm{t}=-0.23, \mathrm{df}=3, \mathrm{P}=0.82, \mathrm{R}^{2}=0.77$ ). The minimal growth was $0.091 \mathrm{~mm} \mathrm{~d}^{-1}$ measured at temperature of $7^{\circ} \mathrm{C}$ and fish daily fed at $5 \%$ of their mass; and, the maximal growth was $0.38 \mathrm{~mm} \mathrm{~d}^{-1}$ at $15.66^{\circ} \mathrm{C}$ and a daily feeding ratio of $80 \%$ of fish mass.

In the experiment 3 (growth of adults under controlled conditions), no significant sex effect was shown (ANCOVA, $\mathrm{F}_{1,71}=3.38, \mathrm{P}=0.07$ ) in the group with small size. However, females were significantly bigger than males for the two other groups (ANCOVA, medium group, $\mathrm{F}_{1,153}=21.64, \mathrm{P}<0.001$ and large group, $\left.\mathrm{F}_{1,162}=345.87, \mathrm{P}<0.001\right)$. The small and medium groups continued to grow during the 55 days in the experiment (ANCOVA, small group, $\mathrm{F}_{1,71}$ $=319.01, \mathrm{P}<0.001 ;$ medium group, $\left.\mathrm{F}_{1,153}=151.00, \mathrm{P}<0.001\right)$ whereas the large group ceased to grow (ANCOVA, $\mathrm{F}_{1,162}=3.81, \mathrm{P}=0.053$ ) because the ultimate length was reached.

349 There is no interaction between sex and time for the small group (ANCOVA, $\mathrm{F}_{1,71}=0.77, \mathrm{P}=$ 350 0.38). In contrast, the growths were not the same between males and females for the medium group $\left(\mathrm{ANCOVA}, \mathrm{F}_{1,153}=9.91, \mathrm{P}=0.002\right)$ and the large group $\left(\mathrm{ANCOVA}, \mathrm{F}_{1,162}=4.40, \mathrm{P}=\right.$ 0.04). The average maximal standard length of G. aculeatus in our experiments was $61.88 \pm$

$3531.86 \mathrm{~mm}($ mean \pm S.D.) for females (range: $59.96-65.02 \mathrm{~mm})$ and $55.51 \pm 2.06 \mathrm{~mm}(\mathrm{mean} \pm$ 354 S.D.) for males (range: $53.94-58.42 \mathrm{~mm}$ ). 
In experiment 4 , the average clutch size in our data was $101.41 \pm 28.38$ eggs (mean \pm S.D., $356 \mathrm{n}=34)$ and the average standard length of females was $48.78 \pm 3.59 \mathrm{~mm}$ (mean \pm S.D., $\mathrm{n}=$

357 34). The clutch size increased with the females' standard length (ANCOVA, $\mathrm{F}_{1,27}=37.32, \mathrm{P}<$ 358 0.001). However, in our experiment, the clutch size was not impacted by the water 359 temperature (ANCOVA, $\left.\mathrm{F}_{2,27}=2.22, \mathrm{P}=0.13\right)$ and by the interaction $\left(\mathrm{ANCOVA}, \mathrm{F}_{2,27}=\right.$ $360 \quad 0.66, \mathrm{P}=0.53)$.

361 Linear model fitted on the clutch size data predicts the length for a female with one egg at $36230.3 \pm 5.01 \mathrm{~mm}(\mathrm{CI}$ at $95 \%$ is from 25.3 to $35.2 \mathrm{~mm}$; clutch size $=\alpha . \mathrm{L}+\beta$, with $\alpha$ equal to 5.37 $363 \pm 0.56$ and $\beta$ equal to $-160.29 \pm 28.72$ ). The length at maturity for the males was similar: $50 \%$ 364 of the males were mature at $33.1 \mathrm{~mm}$ and the smaller mature male in our sample measured $36530.5 \mathrm{~mm}$ (data presented in Supporting Information).

\section{SENSIVITY ANALYSIS}

367 The sensitivity analysis showed that the main influencing parameters on growth were the 368 same for females and for males (Fig. 2; from Fig. 1C and Fig. 2C in Supporting Information 369 C.1). The parameters $\delta_{M}, T_{o p t},\left\{\dot{p}_{A m}\right\}, \kappa,\left[\dot{p}_{M}\right]$ and $\dot{v}$ were the six most influential parameters. 370 The other parameters only slightly influenced growth (Fig. 2A). Regarding reproduction, the 371 parameter $\left\{\dot{p}_{A m}\right\}$ had the largest impact on the number of eggs produced by the females (Fig. 372 2C). This parameter was followed by parameters $T_{\text {opt }},\left[\dot{p}_{M}\right], k_{R}$ and $E_{0}$ for females.

The three Markov chains stabilized around the same distribution for each parameter 375 (Supporting Information C.2 and C.3). Indeed, the Gelman-Rubin was lower than 1.2 for all 376 parameters. The mode of a posteriori parameters distribution is presented in Table 2. A 
posteriori values of parameters differed from a priori ones (Tables 1 and 2) except for the parameter $L_{\text {egg }}$.

379 Growth patterns (juveniles, females and males adults) were accurately described by our

380 DEB model regardless the length (Fig. 3A, B and C), the temperature and the feeding level 381 (Fig. 3). The regression line overlapped the diagonal of the Cartesian plan line (slope $=1$, 382 intercept $=$ 0; Fig. 3D).

383 We estimated a maximal length for females of $63.28 \mathrm{~mm}$ and $56.26 \mathrm{~mm}$ for males and a 384 standard length at maturity of $32.84 \mathrm{~mm}$ for females and males in ad-libitum conditions, at $38523^{\circ} \mathrm{C}$ (optimal temperature). Our model could account for the spawn size and the growth of 386 females (in mm) during the reproduction at different temperatures (Fig. 4).

387 PREDICTIVE CAPACITY

388 Our model predictions and the observations are presented for the growth of juveniles in 389 Fig. 5 and for the reproduction in Fig. 6. A majority of the points of the two growth datasets 390 were in the 95\% confidence interval for model predictions (Fig. 5A and Fig. 5D). The energy 391 density predicted by our DEB model is presented in Fig. 5B for the experiment 1 (May) and 392 in Fig. 5E for the experiment 2 (July); the feeding ratio is presented in Fig. 5C and Fig. 5F. 393 According to our DEB model, the juveniles were actually not fed ad-libitum in the second 394 experiment because the energy density was below $E_{m}$ (maximal energy density)(Fig. 5E). 395 Furthermore, $f$ (the feeding ratio) did also not reach its maximal threshold which is 1 for the 396 second experiment (Fig. 5F).

397 The reproduction (the cumulated number of eggs spawned according to the standard length 398 of females at the time of the spawns) was well-predicted: only three points were not in the $39995 \%$ confidence interval of the model predictions (Fig. 6).

400 DISCUSSION 
In this study, comparing to the bioenergetic model developed by Hover et al. (2015), we 402 proposed a model of the entire life-cycle of $G$. aculeatus using a bioenergetics approach. 403 Moreover, our model predicts reproduction. This model adequately fitted the growth and 404 reproduction data used for its calibration, and predicted well the three other datasets (not used 405 for calibration).

406 The Bayesian calibration of our DEB model for G. aculeatus appeared to be successful 407 despite the relatively high number of parameters in our model. Convergence was reached, as 408 shown by the Gelman-Rubin convergence statistics (Gelman et al. 1996). A Bayesian 409 approach was already used to estimate the parameters of DEB model and showed satisfactory 410 results (Klok et al. 2007; Johnson et al. 2013; Beaudouin et al. 2015). It was also used to 411 estimate parameters in DEBtox model (Billoir et al. 2008; Goussen et al. 2015). Another 412 method using covariance method is usually also performed (Lika et al. 2011a; Lika et al. 413 2011b). This approach is based on the frequentist statistical inference (minimization of a 414 weighted sum of squared, maximum likelihood). The main advantage of the Bayesian 415 approach is that a priori information on the distribution of the parameters can be used, and $a$ 416 posteriori distributions informed on the parameter uncertainties.

417 The a posteriori distributions were different from a priori distribution except for the 418 parameter $\mathrm{L}_{\text {egg. }}$. This denotes that in our dataset and experiments, no information was available 419 to reduce the uncertainty on this parameter, and complementary experiments should be 420 conducted to refine these posterior distributions. For the parameters for which the 421 distributions were updated, part of this update could be explained by biological differences 422 (relative to growth, size at maturity and reproduction) between G. aculeatus used in our 423 experiments and the fish for which data were available to determinate the a priori values of 
424 parameters. G. aculeatus is indeed well-known for its phenotypical plasticity (Baker 1994;

425 McKinnon \& Rundle 2002; Wootton 1984)(Table 1D in Supporting Information D).

426 The temperature range of our experiment was from 11 to $20{ }^{\circ} \mathrm{C}$ for both the growth and the

427 reproduction experiments. Consequently, the range of the temperature in our experiment was

428 too small to update the three parameters of the temperature correction function and avoid

429 over-fitting. We thus decided to exclude the temperature correction from the calibration. We

430 used the temperature correction function defined for warmwater fishes (Kitchell et al. 1977)

431 and adjusted for the stickleback by Hovel et al. (2015). In the case of G. aculeatus, the effect

432 of temperature on growth follows a sharp peak: the growth is maximal at an optimum

433 temperature and decreases at lower and upper temperatures (Hovel et al. 2015). The model we

434 used accounted for this phenomenon and provided accurate predictions of the effects of 435 temperature.

436 Our experimental results are in agreement with the literature. Thus, the growth of fish is

437 well-known to depend on the water temperature and on the amount of food in the 438 environment (Allen \& Wootton 1982; Wootton 1984). Moreover, our predictions of maximal 439 standard length are in conformity with observations in France for female and male $G$. 440 aculeatus (Table 1D, Supporting Information D). However, some observations for the 441 maximal length and the standard length at maturity available in the literature are different 442 from the values we estimated (Table 1D, Supporting Information D). Indeed, most of them 443 were bigger than our estimates for our population studied in experimental river. These 444 differences may be due to the large phenotypic plasticity of $G$. aculeatus (McKinnon \& 445 Rundle 2002) but also to the differences between confounding environmental factors 446 depending on latitude, such as temperature (Baker 1994). Furthermore, the fact that males and 
447 females are sexually mature at the same length is in conformity with the results by Mori \& 448 Nagoshi (1987).

449 For the reproduction part of our model, overall, the model gives accurate predictions which

450 are in accordance with literature data: for instance, as predicted by our model, a female about $45150 \mathrm{~mm}$ long is likely to spawn a hundred eggs (Table 1D, Supporting Information D). 452 However, higher residual errors were observed for some reproduction observations (Fig. 5). 453 The literature shows that the number of eggs depends on several factors in sticklebacks 454 (Wootton 1973b; 1984; 1985; Wootton \& Fletcher 2009), as among others, the actual length of the female (Wootton 1973; Wootton 1976; Kynard 1978; Baker 1994) and food ratio 456 (Wootton 1973a). The food ratio and standard length may be influenced by intraspecific food 457 competition between females in the tank (Gill \& Hart 1996; Milinski 1982; Ward et al. 2006). 458 In G. aculeatus, bigger fish monopolize the prey (Gill \& Hart 1996; Milinski 1982) and 459 subordinate fish have to increase their effort to obtain the same food intake than dominant. 460 Consequently, the net energetic gains may decrease, with consequences for reproductive 461 success (Purser \& Radford 2011). In our case, the subordinate females may have fed less than 462 ad-libitum and may have spawned a number of eggs lower than expected. In addition, clutch 463 size could be reduced because the dominance hierarchies between female may induce an 464 inhibition of the reproductive processes caused by olfactory cues (Paull et al. 2010; 465 Sokolowska \& Kulczykowska 2009). For instance, in Danio rerio, some steroid glucuronides 466 released into the water by males or by females stimulate the reproductive processes of the fish 467 of the opposite sex but also inhibit the reproductive processes of the fish of same sex (Gerlach 468 2006; Lawrence 2007). In G. aculeatus, one study highlighted an increase of genes expression 469 in fish housed in social groups (Greenwood \& Peichel 2015). These genes were responsible 470 for social competition (between individuals for the food resources) and reproductive behavior. 
471 Finally, the stress caused by everyday anthropogenic activities (feeding, observation, capture)

472 can increase experimental variability and have a negative impact on foraging efficiency in $G$.

473 aculeatus (Purser \& Radford 2011). Another source of residual error could be the uncertainty

474 on the estimation of the inter-spawning interval or growth. Indeed, the data used to estimate

475 the ISI came from different G. aculeatus populations living in different habitats with different

476 life strategies (Bolduc \& FitzGerald 1989; Boulé \& Fitzgerald 1989; Wootton et al. 1978) and

477 G. aculeatus is a species of fish widely known for phenotypic plasticity, in particular, relative

478 to reproduction parameters (Wootton 1973; Wootton 1976; Wootton \& Evans 1976; Boulé \&

479 Fitzgerald 1989; Snyder \& Dingle, 1989) (Table 1D, Supporting Information).

Our DEB model could be integrated into an individual-based model of G. aculeatus adding 482 other individual and population processes not predicted by the DEB model (behaviour, 483 interactions with the environment ...). This population model would allow us to predict 484 impact of compounds at the population level in future works aiming at assessing the 485 ecological impact of chemicals on the fish. For this, the DEB model of G. aculeatus will be 486 combined with an individual-based model. DEB-IBM models have already used to others 487 species, and have demonstrated their abilities to extrapolate from ecotoxicological data 488 measured on organisms in laboratory conditions to biological endpoints convenient 489 (Beaudouin et al. 2012; Beaudouin et al. 2015; Martin et al. 2013). Moreover, data on 490 population obtained in our mesocosm (De Kermoysan et al. 2013) could be used to improve 491 the DEB model by giving information on the energy budget in male after maturity and during 492 the reproduction season.

493 ACKNOWLEDGEMENTS 
494 The authors wish to thank the reviewers for the perfectly proof reading and all peoples 495 were contributed to the success of experiments and C. Tebby for her thorough re-reading of 496 this article. This study was supported by the 190 program of the Ministry of Ecology and 497 DOREMIPHARM, funded by ANSM (French National Agency for Medicines and Health 498 Products Safety). 
500 Allen, J. R. M. \& Wootton, R. J. (1982). The effect of ration and temperature on the growth of the three-spined stickleback, Gasterosteus aculeatus L. Journal of Fish Biology 20, 409-422.

502 Augustine, S., Gagnaire, B., Floriani, M., Adam-Guillermin, C. \& Kooijman, S. (2011). Developmental energetics of zebrafish, Danio rerio. Comparative Biochemistry and Physiology Part A: Molecular \& Integrative Physiology 159, 275-283. Baker, J. A. (1994). Life history variation in female threespine stickleback. In The Evolutionary Biology of the Threespine Stickleback (Bell, M. \& Foster, S. A., eds.), pp. 144 - 187: Oxford Science Publications. Beaudouin, R., Dias, V., Bonzom, J. M. \& Péry, A. (2012). Individual-based model of Chironomus riparius population dynamics over several generations to explore adaptation following exposure to uranium-spiked sediments. Ecotoxicology 21, 1225-1239. Beaudouin, R., Goussen, B., Piccini, B., Augustine, S., Devillers, J., Brion, F. \& Péry, A. (2015). An individualbased model of zebrafish population dynamics accounting for energy dynamics. PLoS One.

512 Billoir, E., Delignette-Muller, M. L., Péry, A. R. R., Geffard, O. \& Charles, S. (2008). Statistical cautions when estimating DEBtox parameters. Journal of theoretical biology 254, 55-64.

514 Bois, F. Y. (2009). GNU MCSim. Journal Bioinformatics 25, 1453-1454.

515 Bolduc, F. \& FitzGerald, G. J. (1989). The role of selected environmental factors and sex ratio upon egg production in three-spine sticklebacks, Gasterosteus aculeatus. Canadian Journal of Zoology 67, 2013-2020.

517 Boulé, V. \& Fitzgerald, G. J. (1989). Effects of constant and fluctuating temperatures on egg production in the 518 threespine stickleback (Gasterosteus aculeatus). Canadian Journal of Zoology 67, 1599-1602.

519 Craig-Bennett, A. 1931. The Reproductive Cycle of the Three-Spined Stickleback, Gasterosteus aculeatus, Linn.

520 De Kermoysan, G., Joachim, S., Baudoin, P., Lonjaret, M., Tebby, C., Lesaulnier, F., Lestremau, F., Chatellier, 521 C., Akrour, Z., Pheron, E. \& others (2013). Effects of bisphenol A on different trophic levels in a lotic 522 experimental ecosystem. Aquatic Toxicology 144, 186-198.

523 Einarsson, B., Birnir, B. \& Sigurosson, S. (2011). A dynamic energy budget (DEB) model for the energy usage 524 and reproduction of the Icelandic capelin (Mallotus villosus). Journal of theoretical biology 281, 1-8.

525 Forbes, V. E., Calow, P., Grimm, V., Hayashi, T. I., Jager, T., Katholm, A., Palmqvist, A., Pastorok, R., Salvito, 526 D., Sibly, R. \& others (2011). Adding value to ecological risk assessment with population modeling. Human and 527 Ecological Risk Assessment 17, 287-299. 
528 Freitas, V. n., Cardoso, J. F. M. F., Lika, K., Peck, M. A., Campos, J., Kooijman, S. A. L. M. \& Van der Veer,

529 H. W. (2010). Temperature tolerance and energetics: a dynamic energy budget-based comparison of North

530 Atlantic marine species. Philosophical Transactions of the Royal Society B: Biological Sciences 365, 3553-3565.

531 Gelman, A., Meng, X.-L. \& Stern, H. (1996). Posterior predictive assessment of model fitness via realized

532 discrepancies. Statistica sinica 6, 733-760.

533 Gerlach, G. (2006). Pheromonal regulation of reproductive success in female zebrafish: female suppression and

534 male enhancement. Animal Behaviour 72, 1119-1124.

535 Gill, A. B. \& Hart, P. J. (1996). Unequal competition between three-spined stickleback, Gasterosteus aculeatus,

536 L., encountering sequential prey. Animal Behaviour 51, 689-698.

537 Goussen, B., Beaudouin, R., Dutilleul, M., Buisset-Goussen, A., Bonzom, J.-M. \& Péry, A. R. R. (2015).

538 Energy-based modelling to assess effects of chemicals on Caenorhabditis elegans: A case study on uranium.

539 Chemosphere 120, 507-514.

540 Goussen, B., Parisot, F., Beaudouin, R., Dutilleul, M., Buisset-Goussen, A., Péry, A. R. R. \& Bonzom, J.-M.

541 (2013). Consequences of a multi-generation exposure to uranium on Caenorhabditis elegans life parameters and

542 sensitivity. Ecotoxicology 22, 869-878.

543 Greenwood, A. K. \& Peichel, C. L. (2015). Social Regulation of Gene Expression in Threespine Sticklebacks.

$544 \quad$ PLoS One 10, e0137726.

545 Harmon, L.J., Matthews, B., Des Roches, S., Chase, J.M., J.B., Shurin, J.B., Schluter, D. (2009). Evolutionary

546 diversification in stickleback affects ecosystem functioning. Nature 458, 1167-1170.

547 Hovel, R.A., Beauchamp, D.A., Hansen, A.G., Sorel, M.H. (2015). Development of a bioenergetics model for

548 the threespine stickleback. Transactions of the American Fisheries Society, 144, 1311-1321.

549 Jager, T., Crommentuijn, T., Van Gestel, C. A. M. \& Kooijman, S. A. L. M. (2004). Simultaneous modeling of

550 multiple end points in life-cycle toxicity tests. Environmental science \& technology 38, 2894-2900.

551 Johnson, L. R., Pecquerie, L. \& Nisbet, R. M. (2013). Bayesian inference for bioenergetic models. Ecology 94,

$552 \quad 882-894$.

553 Jusup, M., Klanjscek, T., Matsuda, H. \& Kooijman, S. (2011). A full lifecycle bioenergetic model for bluefin 554 tuna. PLoS One 6. 
555 Klok, C., Holmstrup, M. \& Damgaard, C. (2007). Extending a combined dynamic energy budget matrix 556 population model with a bayesian approach to assess variation in the intrinsic rate of population increase. An

557 example in the earthworm Dendrobaena octaedra. Environmental Toxicology and Chemistry 26, $2383-2388$.

558 Kooijman, S. \& Bedaux, J. J. M. (1996). Analysis of toxicity tests on Daphnia survival and reproduction. Water

559 Research 30, 1711-1723.

560 Kooijman, S. A. L. M. (2000). Dynamic Energy and Mass Budgets in Biological Systems: Cambridge University

561 Press.

562 Kooijman, S. A. L. M. (2010). Dynamic Energy Budget theory for metabolic organisation: Cambridge

563 University Press.

564 Kooijman, S. A. L. M. \& Lika, K. (2014). Resource allocation to reproduction in animals. Biological Reviews $56589,849-859$.

566 Kynard, B. E. (1978). Breeding behavior of a lacustrine population of threespine sticklebacks (Gasterosteus 567 aculeatus L.). Behaviour 67, 178-206.

568 Lefébure, R., Larsson, S. \& Byström, P. (2011). A temperature-dependent growth model for the three-spined 569 stickleback Gasterosteus aculeatus. Journal of Fish Biology 79, 1815-1827.

570 Lika, K., Kearney, M. R., Freitas, V., van der Veer, H. W., van der Meer, J., Wijsman, J. W. M., Pecquerie, L. \& 571 Kooijman, S. A. L. M. (2011a). The "covariation method" for estimating the parameters of the standard Dynamic 572 Energy Budget model I: philosophy and approach. Journal of Sea Research 66, 270-277.

573 Lika, K., Kearney, M. R. \& Kooijman, S. A. L. M. (2011b). The "covariation method" for estimating the 574 parameters of the standard Dynamic Energy Budget model II: Properties and preliminary patterns. Journal of 575 Sea Research 66, 278-288.

576 Martin, B. T., Jager, T., Nisbet, R. M., Preuss, T. G., Hammers-Wirtz, M. \& Grimm, V. (2013). Extrapolating 577 ecotoxicological effects from individuals to populations: a generic approach based on Dynamic Energy Budget 578 theory and individual-based modeling. Ecotoxicology 22, 574-583.

579 Maunder, R. J., Matthiessen, P., Sumpter, J. P. \& Pottinger, T. G. (2007). Impaired reproduction in three-spined 580 sticklebacks exposed to ethinyl estradiol as juveniles. Biology of reproduction 77, 999-1006.

581 McKinnon, J. S. \& Rundle, H. D. (2002). Speciation in nature: the threespine stickleback model systems. Trends 582 in Ecology \& Evolution 17, 480-488. 
583 Milinski, M. (1982). Optimal foraging: the influence of intraspecific competition on diet selection. Behavioral Ecology and Sociobiology 11, 109-115.

585 Mori, S. \& Nagoshi, M. (1987). Growth and maturity size of the three-spined stickleback Gasterosteus aculeatus in rearing pool. Bulletin of the Faculty of Fisheries, Mie University 14, 1-10.

587 Nisbet, R.M., Jusup, M., Klanjscek, T., Pecquerie, L. (2012). Integrating dynamic energy budget (DEB) theory 588 with traditional bioenergetic models. Journal of Experimental Biology 215, 892-902

589 Paull, G. C., Filby, A. L., Giddins, H. G., Coe, T. S., Hamilton, P. B. \& Tyler, C. R. (2010). Dominance 590 hierarchies in zebrafish (Danio rerio) and their relationship with reproductive success. Zebrafish 7, $109-117$.

591 Pecquerie, L., Johnson, L. R., Kooijman, S. A. L. M. \& Nisbet, R. M. (2011). Analyzing variations in life-history 592 traits of Pacific salmon in the context of Dynamic Energy Budget (DEB) theory. Journal of Sea Research 66, $593 \quad 424-433$

594 Pecquerie, L., Petitgas, P. \& Kooijman, S. A. L. M. (2009). Modeling fish growth and reproduction in the 595 context of the Dynamic Energy Budget theory to predict environmental impact on anchovy spawning duration. 596 Journal of Sea Research 62, 93-105.

597 Péry, A. R. R., Ducrot, V., Mons, R. \& Garric, J. (2003). Modelling toxicity and mode of action of chemicals to 598 analyse growth and emergence tests with the midge Chironomus riparius. Aquatic Toxicology 65, $281-292$.

599 Plummer, M., Best, N., Cowles, K., Vines, K., Sarkar, D., Bates, B. \& Almond, R. (2015). coda: Output 600 Analysis and Diagnostics for MCMC.

601 Pottinger, T. G., Carrick, T. R. \& Yeomans, W. E. (2002). The three-spined stickleback as an environmental 602 sentinel: effects of stressors on whole-body physiological indices. Journal of Fish Biology 61, 207-229.

603 Pujol, G., Iooss, B. \& Janon, A. (2012). Sensitivity: Sensitivity Analysis.

604 Purser, J. \& Radford, A. N. (2011). Acoustic Noise Induces Attention Shifts and Reduces Foraging Performance 605 in Three-Spined Sticklebacks (Gasterosteus aculeatus). PLoS One 6, e17478.

606 R Core Team (2014). R: A Language and Environment for Statistical Computing. Foundation for Statistical 607 Computing. Vienna, Austria.

608 Rasband, W. S. (1997). ImageJ, U. S. National Institutes of Health, Bethesda, Maryland, USA.

609 Rinaldi, A., Montalto, V., Lika, K., Sanfilippo, M., Manganaro, A. \& SarÃ, G. (2014). Estimation of dynamic 610 energy budget parameters for the Mediterranean toothcarp (Aphanius fasciatus). Journal of Sea Research 94, 6561170. 
612 Roussel, H.., Joachim, S., Lamothe, S., Palluel, O., Gauthier, L. \& Bonzom, J.-M. (2007a). A long-term copper

613 exposure on freshwater ecosystem using lotic mesocosms: Individual and population responses of three-spined

614 sticklebacks (Gasterosteus aculeatus). Aquatic Toxicology 82, 272-280.

615 Saltelli, A. (2002). Making best use of model evaluations to compute sensitivity indices. Computer Physics

616 Communications 145, 280-297.

617 Santos, R., Palos-Ladeiro, M., Besnard, A., Porcher, J. M., Bony, S., Sanchez, W. \& Devaux, A. (2013a).

618 Relationship between DNA damage in sperm after ex vivo exposure and abnormal embryo development in the

619 progeny of the three-spined stickleback. Reproductive Toxicology 36, 6-11.

620 Santos, R., Palos-Ladeiro, M., Besnard, A., Reggio, J., Vulliet, E., Porcher, J. M., Bony, S., Sanchez, W. \&

621 Devaux, A. (2013b). Parental exposure to methyl methane sulfonate of three-spined stickleback: contribution of

622 DNA damage in male and female germ cells to further development impairment in progeny. Ecotoxicology 22,

$623 \quad 815-824$.

624 Snyder, R. J. \& Dingle, H. (1989). Adaptive, genetically based differences in life history between estuary and 625 freshwater threespine sticklebacks (Gasterosteus aculeatus L.). Canadian Journal of Zoology 67, 2448-2454.

626 Sokolowska, E. \& Kulczykowska, E. (2009). Environmental influence on maturation and dominance

627 relationships in the three-spined stickleback (Gasterosteus aculeatus L.): temperature competes with photoperiod

628 for primacy. Oceanological and Hydrobiological Studies 38, 31-48

629 Sokolowska, E. \& Kulczykowska, E. 2006. Annual reproductive cycle in two free living populations of three-

630 spined stickleback (Gasterosteus aculeatus L.): patterns of ovarian and testicular development. Oceanologia 48.

631 van der Veer, H. W., Kooijman, S. A. L. M. \& van der Meer, J. (2001). Intra-and interspecies comparison of

632 energy flow in North Atlantic flatfish species by means of dynamic energy budgets. Journal of Sea Research $\mathbf{4 5}$,

$633 \quad 303-320$.

634 Ward, A. J. W., Webster, M. M. \& Hart, P. J. B. (2006). Intraspecific food competition in fishes. Fish and 635 Fisheries 7, 231-261.

636 Wootton, R. J. (1973a). The effect of size of food ration on egg production in the female three-spined 637 stickleback, Gasterosteus aculeatus L. Journal of Fish Biology 5, 89-96.

638 Wootton, R. J. (1973b). Fecundity of the three-spined stickleback, Gasterosteus aculeatus (L.). Journal of Fish 639 Biology 5, 683-688.

640 Wootton, R. J. (1976). Biology of the sticklebacks: Academic Press. 
641 Wootton, R. J. (1984). A functional biology of Sticklebacks: CROOM HELM London \& Sydney.

642 Wootton, R. J. (1985). Effects of food and density on the reproductive biology of the threespine stickleback with

643 a hypothesis on population limitation in sticklebacks. Behaviour, 101-111.

644 Wootton, R. J. (1994). Energy allocation in the threespine stickleback. In The evolutionary biology of the 645 Threespined stickleback, pp. 114 - 143: Oxford University Press.

646 Wootton, R. J., Allen, J. R. M. \& Cole, S. J. (1980). Energetics of the annual reproductive cycle in female 647 sticklebacks, Gasterosteus aculeatus L. Journal of Fish Biology 17, 387-394.

648 Wootton, R. J. \& Evans, G. W. (1976). Cost of egg production in the three-spined stickleback (Gasterosteus 649 aculeatus L.). Journal of Fish Biology 8, 385-395.

650 Wootton, R. J., Evans, G. W. \& Mills, L. (1978). Annual cycle in female three-spined sticklebacks (Gasterosteus 651 aculeatus L.) from an upland and lowland population. Journal of Fish Biology 12, 331-343.

652 Wootton, R. J. \& Fletcher, D. A. (2009). Effect of spawning number and ration on reproductive performance of 653 the batch-spawning three-spined stickleback Gasterosteus aculeatus. Journal of Fish Biology 75, 618-629. 


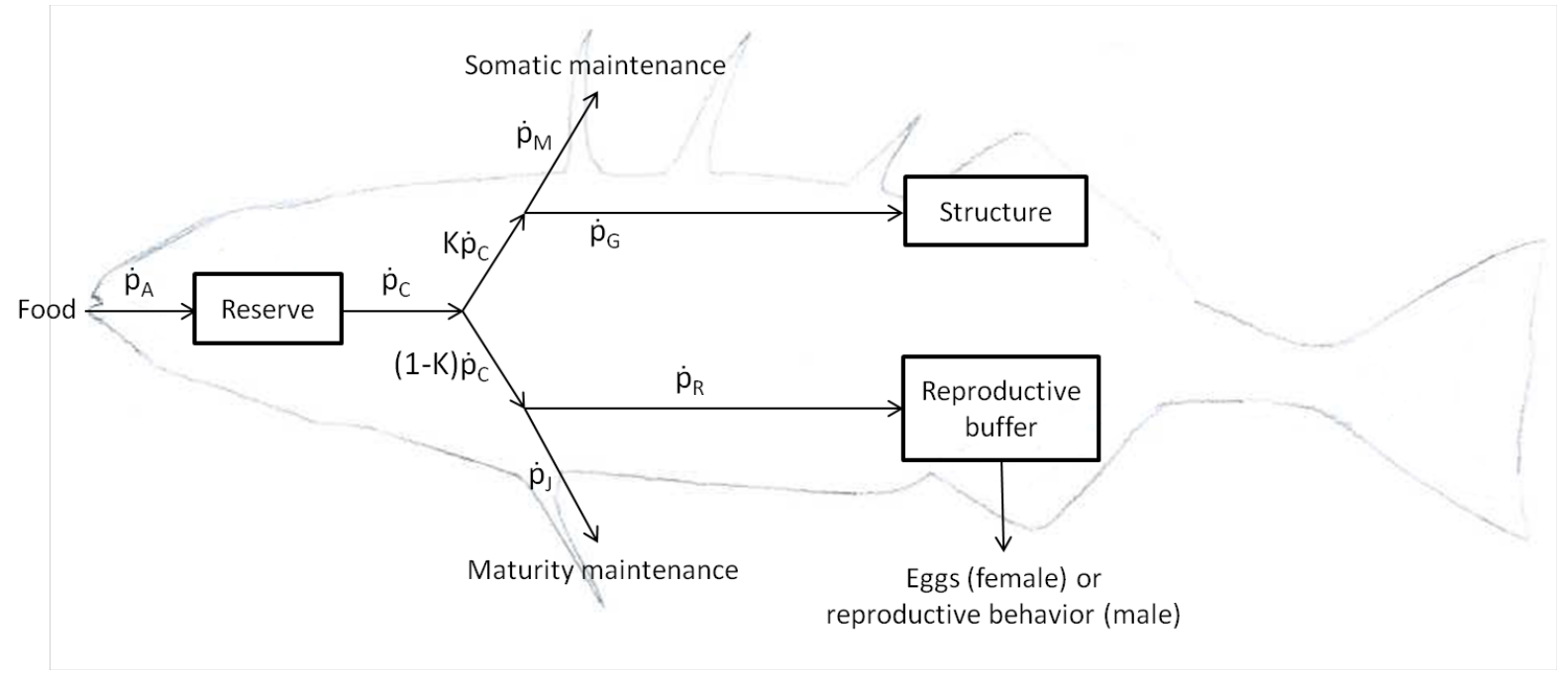

657 Fig. 1. Schematic representation of the dynamic energy budget model of three-spined 658 stickleback. $\dot{p}_{A}$ represents energy assimilated from food and $\dot{p}_{C}$ represents the energy used 659 from reserve. $K$ is the fraction of energy allocated to growth and somatic maintenance. $\dot{p}_{M}, \dot{p}_{G}$, $660 \dot{p}_{J}$ and $\dot{p}_{R}$ represent the energy flux allocated to somatic maintenance, growth, maturity 661 maintenance and reproduction, respectively.
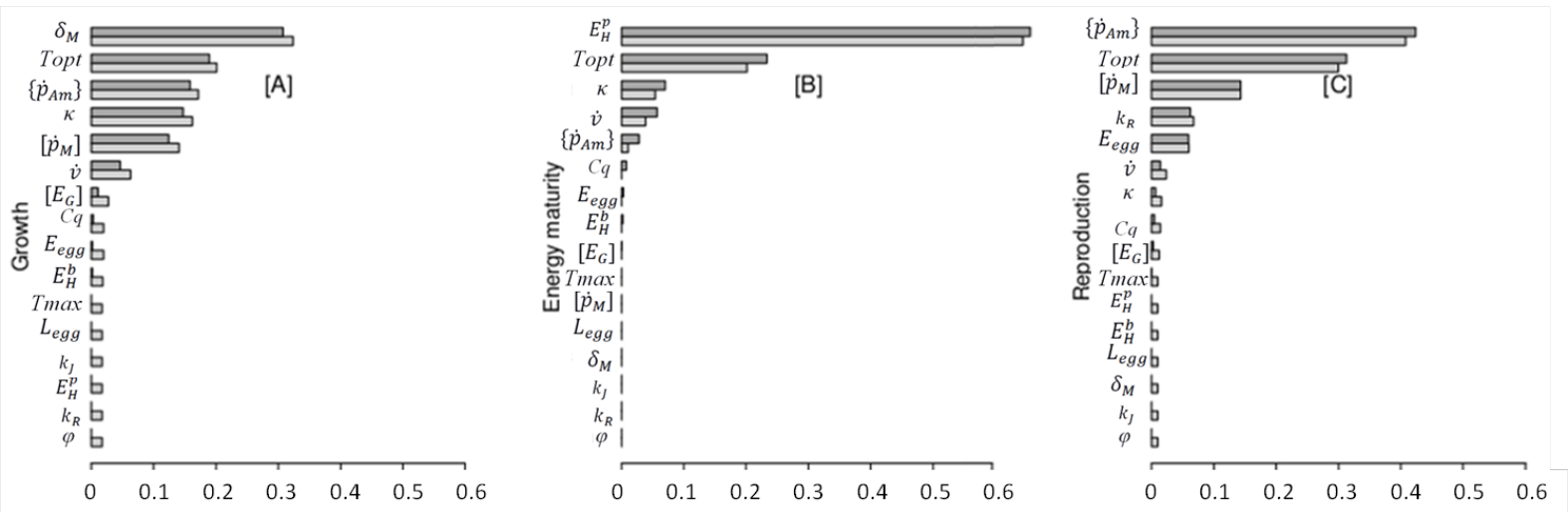

664 Fig. 2. Sensitivity analysis of the DEB model. The Sobol' sensitivity indices are presented 665 for the males for the growth (A), the energy invested in maturity (B), and the energy invested 666 in reproduction $(\mathrm{C})$. 
667 Sobol indices were computed for the growth at 20, 100 and $650 \mathrm{dpf}$, for the energy 668 invested in maturity at 20,50 and $150 \mathrm{dpf}$, and for the energy invested in reproduction at 150 ,

669400 and $650 \mathrm{dpf}$. The water temperature was fixed at $20^{\circ} \mathrm{C}$ and the food was ad-libitum $(\mathrm{f}=1)$.

670 Mean of the indices were presented. The total order indices (TI) are presented in dark grey 671 and first order indices (FOI) in light grey. Parameters were ordered according to the total 672 order sensitivity indices.

(a)

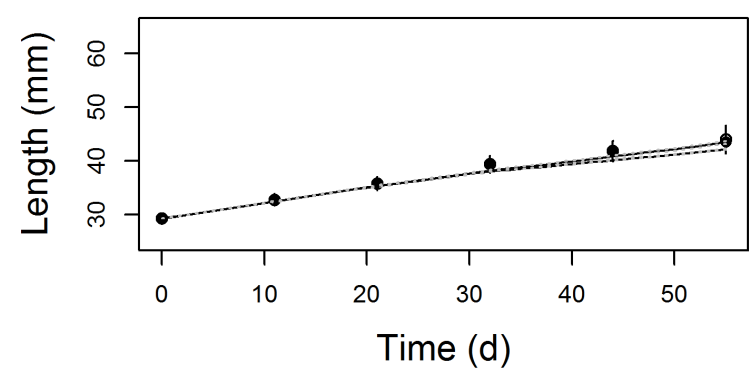

(c)

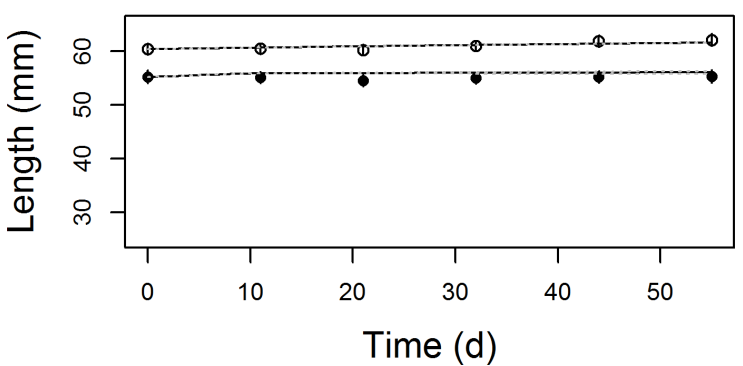

(b)

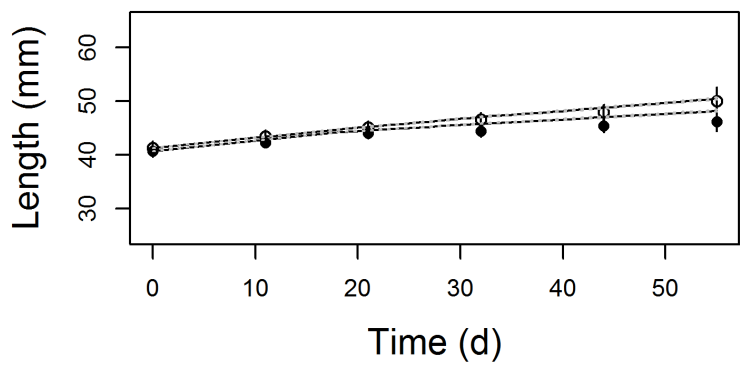

(d)

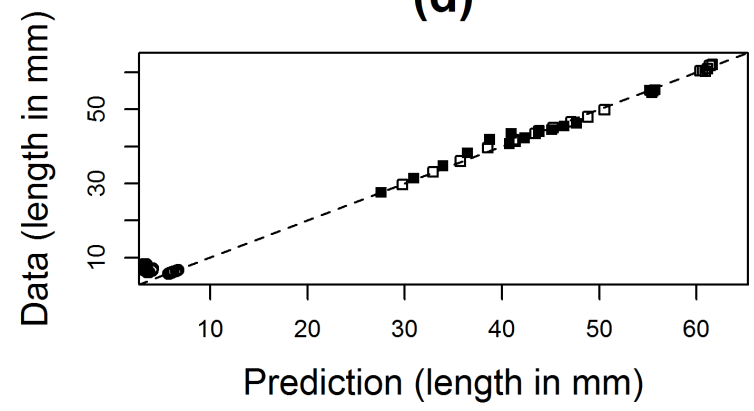

674 Fig. 3. Model predictions using the posterior distributions compared to observed standard

675 lengths of fish (snout till end of caudal fin): (A) small fish group, (B) medium fish group and

676 (C) large fish group; monitored for 55 days. $\circ$ and $\bullet$ represent the mean length of females and 677 males, respectively. The error bar represents the 95\% C.I. of the mean (S.E.). Full lines 678 represent the median and dotted grey lines represent the $95 \%$ C.I. of the model predictions for 679 females and males, respectively. 95\% C.I. of predictions were computed from the posterior 680 distributions. Fig. (D) represents the observations and model predictions (median) for all the 
681 growth data. The dotted line is the bisector and $\circ, \square$ and $\boldsymbol{\square}$ are the means of observations for 682 juveniles, females and males respectively for all experiments.

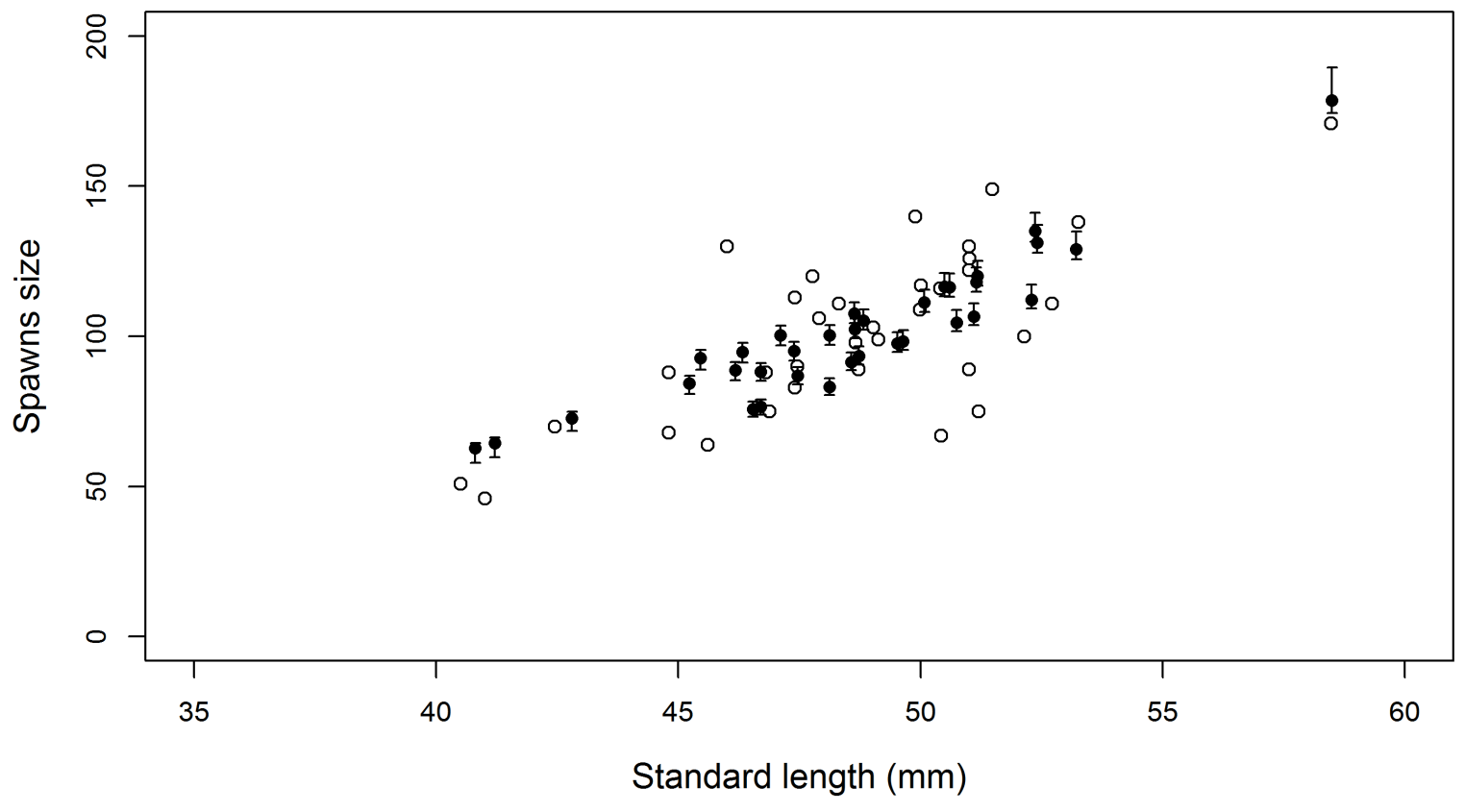

684 Fig. 4. Model predictions versus observations for the number of eggs spawned according 685 to the standard length of females at the time of the spawns. $\circ$ represent the observations (one 686 female per points under different water temperature) and $\bullet$ represent the predictions using the 687 mode of posterior distributions. The error bars represent the 95\% C.I. of the predictions 688 computed from the posterior distributions. Data were recorded under ad-libitum food regime 689 and different water temperature scenarios. 

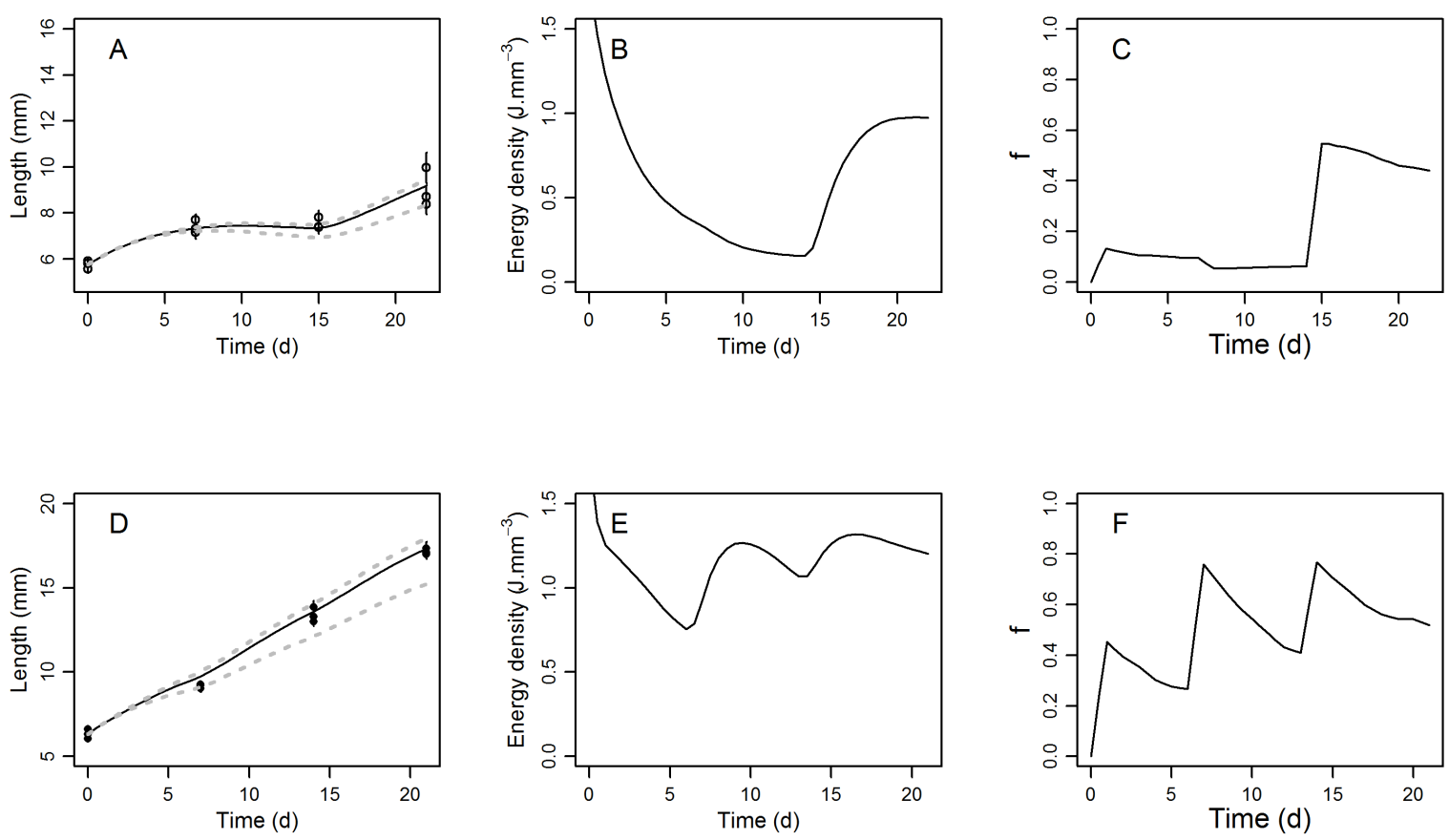

691 Fig. 5. Assessment of the predictive capacity of the model for the growth: model 692 predictions compared to the observed mean length of fish for the experiment 1 (A) and 2 (D).

$693 \circ$ and $\bullet$ represent the observations for the experiment 1 and 2 respectively. The error bars 694 represent the 95\% C.I. of the observations. Full lines represent the median and dotted grey 695 lines represent the $95 \%$ C.I. of the model predictions. 95\% C.I. of predictions were computed 696 from the posterior distributions. Fig. (B) and (E) represent the model predictions for the 697 energy density $\left(\mathrm{J} \cdot \mathrm{mm}^{-3}\right)$. Full lines represent the median for the energy density and dotted red 698 lines are the maximal energy density in a fish. Fig. (C) and (F) represent the feeding ratio (F) 699 during the experiments. Values are comprised between 0 and 1. 


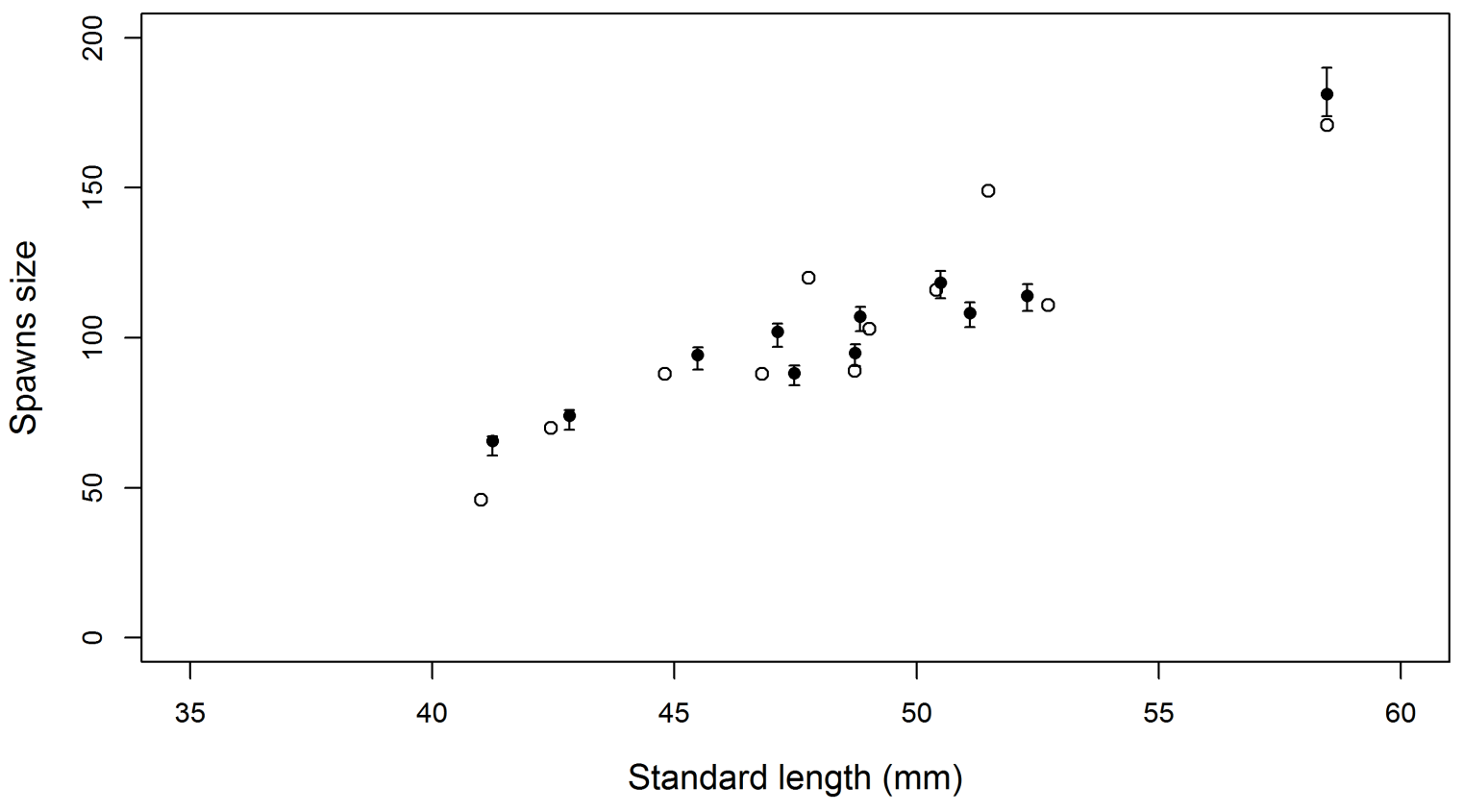

701 Fig. 6. Assessment of the predictive capacity of the model for the female reproduction: 702 model predictions compared to the cumulated number of eggs observed (data not used for 703 calibration process) as a function of standard length at the time of the spawns. $\bullet$ represent the 704 observations (one female per point with different water temperatures) and $\circ$ represent the 705 predictions using the mode of posterior distributions. The error bars represent the $95 \%$ C.I. of 706 the predictions computed from the posterior distributions. Data were recorded under ad707 libitum food regime and different water temperature scenarios. 
Table 1. A priori distributions of the parameters of the stickleback DEB model

\begin{tabular}{|c|c|c|c|c|c|}
\hline$\overline{\text { Symbols }}$ & Distribution & Bounds & Definition & Unit & References \\
\hline$\delta_{M}$ & $\mathrm{~N}(0.25,0.025)$ & $0.2-0.3$ & Shape coefficient for adults & - & Fitted on our data \\
\hline$E_{0}$ & $\mathrm{~N}(8,1)$ & $5-11$ & Initial reserve & $\mathrm{J}$ & Wootton, 1984; Wootton, 1994, fitted \\
\hline$E_{H}^{b}$ & $\mathrm{~N}(0.675,0.3)$ & $0.00001-3$ & Cumulated energy invested in maturity at birth & $\mathrm{J}$ & Addmypet \\
\hline$E_{H}^{p}$ & $\mathrm{~N}(1000,250)$ & $100-1900$ & Cumulated energy invested in maturity at puberty & $\mathrm{J}$ & Addmypet \\
\hline$\left\{\dot{p}_{A m}\right\}$ & $\mathrm{N}(1.5,0.5)$ & $0.01-6$ & Maximum surface area specific assimilation rate & $\mathrm{J} \mathrm{mm}^{-2} \mathrm{~d}^{-1}$ & Addmypet \\
\hline$\dot{v}$ & $\mathrm{~N}(1.25,0.5)$ & $0.01-3.5$ & Energy conductance & $\mathrm{mm} \mathrm{d}^{-1}$ & Addmypet \\
\hline$\alpha$ & $\mathrm{U}(0,1)$ & $0-1$ & Fraction subtracted to $\kappa$ for obtain $\kappa$ in males & - & - \\
\hline$\kappa$ & $\mathrm{N}(0.7,0.1)$ & $0.5-0.9999$ & $\begin{array}{l}\text { Specific fraction of energy mobilized from reserve allocated to growth and somatic } \\
\text { maintenance }\end{array}$ & - & Addmypet \\
\hline$L_{e g g}$ & $\mathrm{~N}(0.55,0.05)$ & $0.2-0.9$ & Size of primordial cell & $\mathrm{mm}$ & Wallace and Selman, 1979; Baker, 199 . \\
\hline$\left[\dot{p}_{M}\right]$ & $\mathrm{N}(0.07,0.1)$ & $0.001-0.3$ & Volume specific somatic maintenance costs & $\mathrm{J} \mathrm{mm}^{-3} \mathrm{~d}^{-1}$ & Addmypet \\
\hline$\left[E_{G}\right]$ & $\mathrm{N}(5.2,2.5)$ & $0.001-10$ & Cost of synthesis of a unit of structure & $\mathrm{J} \mathrm{mm}^{-3}$ & Addmypet \\
\hline$\dot{k}_{J}$ & $\mathrm{~N}(0.002,0.1)$ & $0-0.5$ & Maturity maintenance rate & $\mathrm{d}^{-1}$ & Addmypet \\
\hline$k_{R}$ & $\mathrm{~N}(0.95,0.1)$ & $0-1$ & Reproduction efficiency & - & Addmypet \\
\hline$\varphi$ & $\mathrm{N}(17,1.7)$ & $0-30$ & Feeding frequencies during a day to be fed ad-libitum & - & Hovel et al. (2015) \\
\hline $\operatorname{Tmax}$ & 25 & - & Water temperature above which consumption ceases & ${ }^{\circ} \mathrm{C}$ & Hovel et al. (2015) - Non fitted \\
\hline $\mathrm{Cq}$ & 3 & - & Rate at which the function increases over low temperatures & - & Hovel et al. (2015) - Non fitted \\
\hline Topt & 23 & - & Water temperature preferendum & ${ }^{\circ} \mathrm{C}$ & Hovel et al. (2015) - Non fitted \\
\hline$F_{c}$ & $\mathrm{~N}(1,0.2)$ & - & Uncertainty on the artemia nauplii energy (energy density and allometric relationship) & - & \\
\hline
\end{tabular}

709 
Table 2. Mode and standard deviation of the a posteriori parameters of the DEB model 711

\begin{tabular}{cccc}
\hline Parameter & Mode & SD & Unit \\
\hline$\delta_{M}$ & 0.247 & 0.016 & - \\
$E_{0}$ & 5.72 & 0.56 & $J$ \\
$E_{H}^{b}$ & 1.39 & 0.22 & $J$ \\
$E_{H}^{p}$ & 459 & 165 & $J$ \\
$\left\{\dot{p}_{\text {Am }}\right\}$ & 2.46 & 0.17 & $\mathrm{~J} \mathrm{~mm}^{-2} \mathrm{~d}^{-1}$ \\
$\dot{v}$ & 1.26 & 0.08 & $\mathrm{~mm} \mathrm{~d}^{-1}$ \\
$\kappa$ & 0.752 & 0.028 & - \\
$\alpha$ & 0.079 & 0.004 & - \\
$L_{\text {egg }}$ & 0.551 & 0.05 & $\mathrm{~mm}^{-3}$ \\
{$\left[\dot{p}_{M}\right]$} & 0.119 & 0.01 & $\mathrm{~J} \mathrm{~mm}^{-3} \mathrm{~d}^{-1}$ \\
{$\left[E_{G}\right]$} & 0.972 & 0.12 & $\mathrm{~J} \mathrm{~mm}^{-3}$ \\
$\dot{k}_{J}$ & 0.00056 & 0.005 & $\mathrm{~d}^{-1}$ \\
$k_{R}$ & 0.962 & 0.05 & - \\
Tmax & 25 & - & ${ }^{\circ} \mathrm{C}$ \\
$C q$ & 3 & - & - \\
Topt & 23 & - & ${ }^{\circ} \mathrm{C}$ \\
$\varphi$ & 16.76 & 1.69 & - \\
Fc & 1.20 & 0.18 & - \\
Sigma C & 0.293 & 0.015 & - \\
\hline & & &
\end{tabular}

712

713

714

715

716

717 